\title{
One-Year Outcomes of Peripheral Endovascular Device Intervention in Critical Limb Ischemia Patients: Sub-Analysis of the LIBERTY 360 Study
}

This article was published in the following Dove Press journal: Vascular Health and Risk Management

\author{
Jihad A Mustapha $\mathbb{D}^{1,2}$ \\ Zsuzsanna Igyarto ${ }^{3}$ \\ David O'Connor ${ }^{4}$ \\ Ehrin J Armstrong ${ }^{5,6}$ \\ Anthony R lorio ${ }^{7}$ \\ Vickie R Driver (iD ${ }^{8}$ \\ Fadi Saab ${ }^{2}$ \\ Ann N Behrens ${ }^{3}$ \\ Brad J Martinsen (D) ${ }^{3}$ \\ George L Adams ${ }^{9}$ \\ 'College of Osteopathic Medicine, \\ Michigan State University, E. Lansing, MI, \\ USA $;{ }^{2}$ Advanced Cardiac \& Vascular \\ Amputation Prevention Centers, Grand \\ Rapids, MI, USA; ${ }^{3}$ Cardiovascular \\ Systems, Inc., St. Paul, MN, USA; \\ ${ }^{4}$ Hackensack University Medical Center, \\ Hackensack, NJ, USA; ${ }^{5}$ Denver VA \\ Medical Center, Denver, CO, USA; \\ ${ }^{6}$ Anschutz Medical Campus, University of \\ Colorado, Denver, CO, USA; ${ }^{7}$ Foot \\ Center of New York, New York College \\ of Podiatric Medicine, New York, NY, \\ USA; ${ }^{8}$ Department of Orthopedics, \\ Brown University School of Medicine, \\ Providence, RI, USA; ${ }^{9}$ North Carolina \\ Heart and Vascular, Rex Hospital, UNC \\ School of Medicine, Raleigh, NC, USA
}

Correspondence: Jihad A Mustapha Advanced Cardiac \& Vascular Amputation Prevention Centers, 1525 East Beltline NE, Suite I0I, Grand Rapids, MI 49525, USA

Tel + I 616-447-8220

Email jihadmustapha@acvcenters.com
Background: High-risk patients with advanced peripheral artery disease (PAD), including critical limb ischemia (CLI), are often excluded from peripheral endovascular device intervention clinical trials, leading to difficulty in translating trial results into real-world practice. There is a need for prospectively assessed studies to evaluate peripheral endovascular device intervention outcomes in CLI patients.

Methods: LIBERTY 360 is a prospective, observational, multi-center study designed to evaluate the procedural and long-term clinical outcomes of peripheral endovascular device intervention in real-world patients with symptomatic lower-extremity PAD. One thousand two hundred and four patients were enrolled and stratified based on Rutherford Classification (RC): RC2-3 (N=501), RC4-5 ( $\mathrm{N}=603)$, and RC6 $(\mathrm{N}=100)$. For this sub-analysis, RC5 and RC6 patients (RC5-6; N=404) were pooled and 1-year outcomes were assessed.

Results: Procedural complications rarely $(1.7 \%)$ resulted in post-procedural hospitalization and $89.1 \%$ of RC5-6 patients were discharged to home. Considering the advanced disease state in RC5-6 patients, there was a high freedom from 1-year major adverse event rate of $65.5 \%$ (defined as target vessel revascularization, death to 30 days, and major target limb amputation). At 1 year, freedom from major amputation was $89.6 \%$. Wounds identified at baseline on the target limb had completely healed in 172/243 (70.8\%) of the RC5-6 subjects by 1 year. Additionally, the overall quality of life, as measured by VascuQoL, improved from baseline to 1 year.

Conclusion: LIBERTY investigated real-world PAD patients with independent oversight of outcomes. This analysis of LIBERTY RC5-6 patients demonstrates that peripheral endovascular device intervention can be successful in CLI patients, with low rates of major amputation and improvement in wound healing and quality of life through 1-year follow-up.

LIBERTY 360, https://clinicaltrials.gov/ct2/show/NCT01855412, ClinicalTrials.gov Identifier: NCT01855412.

Keywords: amputation, critical limb ischemia, CLI, endovascular therapy

\section{Introduction}

Approximately 18 million Americans have peripheral artery disease (PAD) and 2 million of these patients suffer from critical limb ischemia (CLI), ${ }^{1,2}$ the end stage of PAD. ${ }^{3}$ CLI is highly prevalent in older patients with diabetes and/or end-stage renal disease ${ }^{4}$ and is associated with high risk of amputation and mortality. ${ }^{5}$ The results following lower extremity amputation can be devastating $-27 \%$ of these patients will have one or more re-amputation(s) within 1 year, ${ }^{6} 35 \%$ will have a higher level of limb loss, ${ }^{7}$ and $55 \%$ will have a contralateral limb amputation within 2-3 years. ${ }^{8}$ Furthermore, the mortality rates 
after primary amputation are very high, with rates ranging from 9 to $33 \%$ at 1 year ${ }^{6,7,9,10}$ and 26 to $82 \%$ at 5 years. ${ }^{6,9-11}$ Despite such devastating outcomes, primary amputation remains a common treatment modality for CLI.

The 2016 AHA/ACC Guideline on the management of patients with lower extremity PAD now recommends an evaluation for revascularization options by an interdisciplinary care team before amputation in CLI patients (Class I). ${ }^{12}$ Interestingly, recent studies demonstrate an increased utilization of endovascular intervention as a first-line approach for CLI patients in the US with a corresponding decrease of inhospital death and major amputation. ${ }^{13-15}$

CLI patients, in particular, Rutherford Class 5-6 (RC56) patients with ischemic ulcerations or gangrene, are often excluded or under-represented in endovascular intervention clinical trials given their multiple comorbidities and advanced PAD. To the best of our knowledge, no endovascular device clinical studies in the US have been conducted specifically for RC5-6 patients.

In this sub-analysis of the LIBERTY 360 study, we aimed to investigate outcomes through 1 year in CLI RC56 patients treated with endovascular intervention.

\section{Materials and Methods}

\section{Study Design and Patient Selection}

The LIBERTY 360 study design has been previously described. ${ }^{16,17}$ Briefly, patients were eligible for the study if they were at least 18 years old and had clinical evidence of PAD (Rutherford classification 2 to 6) that required endovascular interventions on one or both limbs that included a target lesion in a native vessel located within or extending into $10 \mathrm{~cm}$ above the medial epicondyle to the digital arteries. Patients were excluded from the study if (1) they required a conversion from endovascular intervention to a surgical bypass graft for any lesion in the target area, (2) had an in-stent restenosis in the target area, and this lesion was the only one requiring treatment, or (3) had an anticipated life span of less than 1 year. The study included any FDA-approved technology to treat claudication and CLI. A total of 1204 patients were enrolled at 51 US sites and divided into three groups based on Rutherford Classification (RC): RC2-3 ( $\mathrm{N}=501), \mathrm{RC} 4-5(\mathrm{~N}=603)$, and RC6 $(\mathrm{N}=100)$. The list of participating institutions is provided in Supplementary Appendix 1. Sites were required to comply with the principles of Good Clinical Practices and meet the World Medical Association Declaration of Helsinki requirements. The study protocol was approved by the Institutional Review Board at each participating institution, and all patients gave written informed consent. Patients were followed up in clinic at 30 days, 6 months, and 1 year. For this sub-analysis, RC5 and RC6 patients $(\mathrm{N}=404)$ were pooled and 1-year outcomes were assessed.

\section{Endpoints}

Procedural success was defined as a final post-procedural result of less than $50 \%$ residual stenosis for all treated lesions during index procedure without significant angiographic complications (flow-limiting dissection, perforation, distal embolization, acute vessel closure) as determined by the angiographic core laboratory (SynvaCor, Springfield, IL). Lesion success was defined as a final post-procedural result of less than $50 \%$ residual stenosis for a given lesion treated during the index procedure and without significant angiographic complications as determined by the angiographic core laboratory. Major adverse events were defined as a composite of (1) death within 30 days of index procedure, (2) unplanned major (above the ankle) amputation of the target limb, or (3) target vessel revascularization as assessed by the angiographic core laboratory when angiographic images were available. Changes in quality of life (QoL) from baseline were analyzed using the Vascular Quality of Life Questionnaire (VascuQoL, measures PAD related health status). Wounds and wound care visits were assessed on the target limb only; wound status (including wound healing) was collected in-office at 30 days, 6 months, and 12 months.

\section{Statistical Analysis}

Data analysis was performed with the SAS Software System (SAS Institute, Inc., Cary, NC). Data are reported as percentage or mean \pm standard deviation. For categorical responses, p-values were approximated using a Monte Carlo Approximation of the Fisher's Exact Test. For ordinal categorical or yes/no responses, p-values were calculated using McNemar's Test. For continuous variables, p-values were calculated using a paired $t$-test or ANOVA. Imputation of significant angiographic complications for procedural and lesion success of core lab identified lesions were performed by using site data when the core lab was unable to perform angiographic assessment. Kaplan-Meier method used to obtain estimate of survival rate. Greenwood's method used to obtain the $95 \%$ confidence interval for the estimate. The statistical significance was set at $\mathrm{p}<0.05$. 


\section{Results}

\section{Patient Characteristics}

Patient demographics and baseline characteristics are included in Table 1. Most patients were white males with high prevalence of hypertension, hyperlipidemia, and diabetes. Fiftyseven percent of patients had coronary artery disease and $14.6 \%$ had chronic kidney disease requiring hemodialysis.

Table I Demographics and Baseline Characteristics

\begin{tabular}{|c|c|}
\hline & $\begin{array}{l}\text { Rutherford 5-6 } \\
(\mathrm{N}=404)\end{array}$ \\
\hline Age (years) & $\begin{array}{l}69.2 \pm 11.6 \\
69.0[62.0,78.0](\mathrm{N}=403)\end{array}$ \\
\hline Male sex & $272(67.3)$ \\
\hline $\begin{array}{l}\text { Race } \\
\text { White } \\
\text { Black or African American } \\
\text { American Indian or Alaska Native } \\
\text { Asian } \\
\text { Other }^{\mathrm{a}}\end{array}$ & $\begin{array}{l}316(78.2) \\
77(19.1) \\
3(0.7) \\
2(0.5) \\
6(1.5)\end{array}$ \\
\hline Body mass index $\left(\mathrm{kg} / \mathrm{m}^{2}\right)$ & $\begin{array}{l}29.4 \pm 6.6 \\
28.3[24.7,33.4]\end{array}$ \\
\hline Current or former smoker & $245(60.6)$ \\
\hline $\begin{array}{l}\text { History of: } \\
\text { Diabetes } \\
\text { Hyperlipidemia } \\
\text { Hypertension } \\
\text { Chronic renal disease } \\
\text { Coronary artery disease }\end{array}$ & $\begin{array}{l}315(78.0) \\
326(80.7) \\
372(92.1) \\
168(41.6) \\
229(56.7)\end{array}$ \\
\hline $\begin{array}{l}\text { Prior endovascular treatment of target } \\
\text { limb }\end{array}$ & I I 8/403 (29.3) \\
\hline $\begin{array}{l}\text { Previous amputation } \\
\text { Both limbs } \\
\text { Target limb } \\
\text { Non-target limb } \\
\text { None }\end{array}$ & $\begin{array}{l}N=404 \\
23(5.7) \\
47(11.6) \\
57(14.1) \\
277(68.6)\end{array}$ \\
\hline $\begin{array}{l}\text { Highest level of prior target limb } \\
\text { amputation }\end{array}$ & $N=70$ \\
\hline Toe(s) only & $66(94.3)$ \\
\hline Foot only & $4(5.7)$ \\
\hline $\begin{array}{l}\text { Highest level of prior contralateral } \\
\text { limb amputation }\end{array}$ & $N=80$ \\
\hline Toe(s) only & $39(48.8)$ \\
\hline Foot only & $3(3.8)$ \\
\hline Below knee/above ankle & $28(35.0)$ \\
\hline Above the knee & $10(12.5)$ \\
\hline
\end{tabular}

Notes: Data provided as mean \pm standard deviation/median [IQR] or number (percentage) as appropriate. ${ }^{\mathrm{a}} \mathrm{O}$ ther race includes patients with more than one race category reported.
Almost half of the patients $(47 \%)$ had previous drug therapy for PAD and $43.6 \%$ had previous lower-limb endovascular treatment for PAD. Patients with prior lower-limb endovascular treatments had a mean number of $1.3 \pm 1.8$ lower-limb procedures on their target limb in the prior 3 years. Thirty-one percent of the patients had previous amputations and 9.4\% had previous major contralateral limb amputations.

\section{Lesion Characteristics and Treatment}

More than $76 \%$ of target lesions were located below-the-knee (Supplementary Table 1). On average, $1.4 \pm 0.7$ lesions were treated per subject. Approximately $60 \%$ of the lesions were calcified and $73.8 \%$ of calcified lesions were moderate to severely calcified per PARC definition. ${ }^{18}$ As shown in Figure 1, balloon and/or atherectomy were the preferred devices. Percutaneous transluminal angioplasty and the orbital atherectomy system were the most frequently used devices in almost $79 \%$ and $48 \%$ of the lesions, respectively. Stents were used in $17 \%$ of the lesions but with minimal bailout stenting due to angiographic complications or suboptimal result $(4.6 \%)$.

\section{Procedural and Lesion Success}

Procedural success was $76.0 \% ; 83.6 \%$ of patients had less than $50 \%$ final residual stenosis in all target lesions treated and $88.8 \%$ had no severe angiographic complications. Lesion success is presented in Supplementary Table 1.

\section{Discharge Status and Medications}

Procedural complications rarely $(1.7 \%)$ resulted in postprocedural hospitalization and $89.1 \%$ of patients were discharged to home. Subjects were taking the following medications at the time of discharge: $91.6 \%$ antiplatelet therapy, $10.9 \%$ anti-coagulants, $74.8 \%$ anti-hyperlipidemic, and $88.4 \%$ anti-hypertensive.

\section{Change in Rutherford Category and Quality of Life}

RC5-6 patients showed a marked improvement from baseline to 12 months (Supplementary Figure 1). Quality of life improved significantly from baseline to 12 months, as measured by the total score and all subdomains of the VascuQoL (Figure 2) and EQ-5D ( $<0.001)$.

\section{Major Adverse Events and Amputation Free Survival at 12 Months}

Freedom from MAEs and amputation free survival is presented in Figure 3 and Table 2. Considering the advanced 


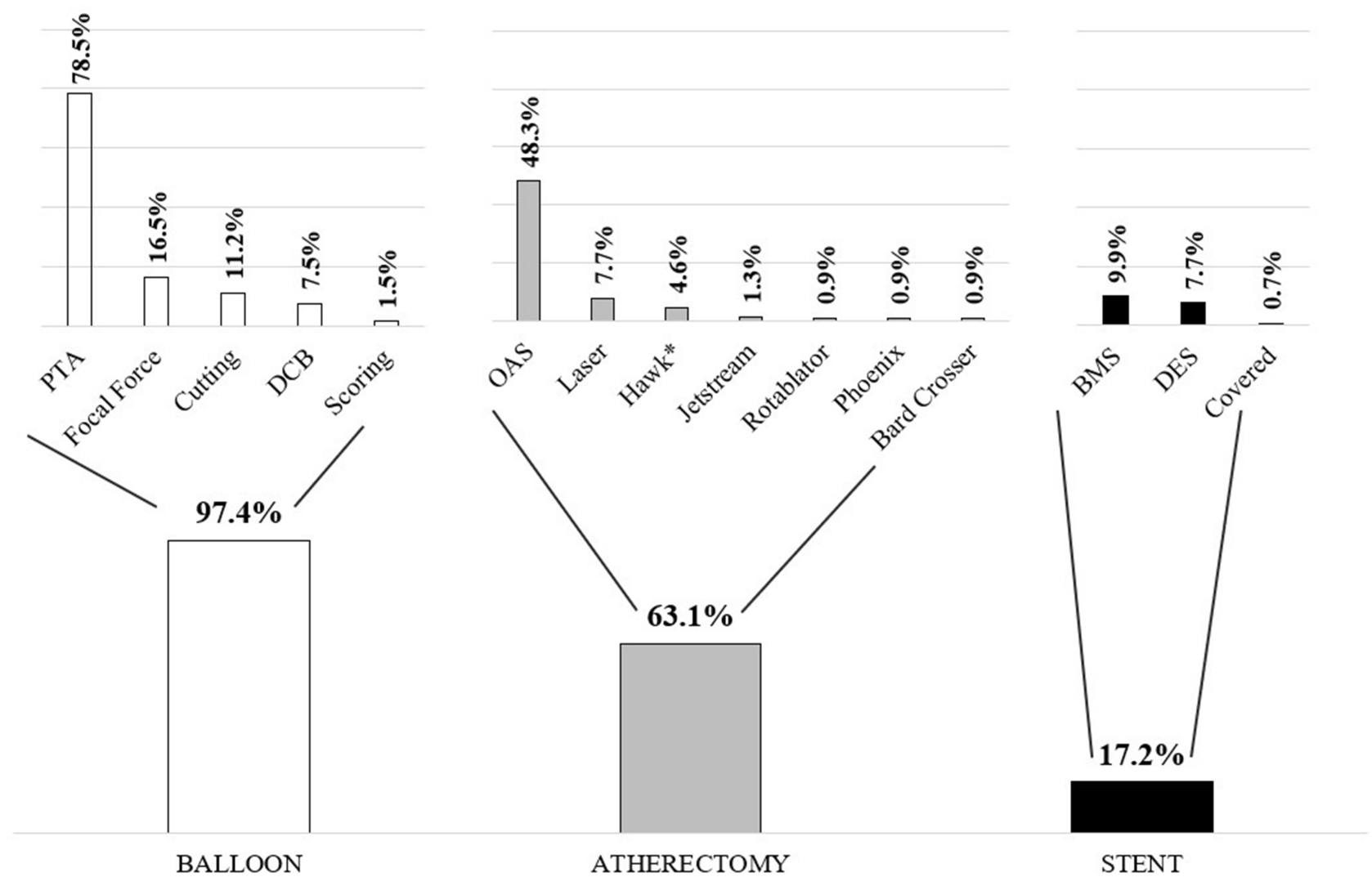

Figure I Device usage by lesion $(\mathrm{N}=558)$ assessed by angiographic core lab. *Hawk: Turbohawk, Silverhawk, Hawk One.

Abbreviations: BMS, bare-metal stent; DCB, drug-coated balloon; DES, drug-eluting stent; OAS, orbital atherectomy system; PTA, percutaneous transluminal angioplasty.

disease state in RC5-6 patients, there were high rates of 12-month amputation free survival (78.2\%) and freedom from major target limb amputation (89.6\%).

\section{Wound Healing on Target Limb}

Significant improvement was noted in the number of wounds from baseline to 12 months (Table 3). At 12 months, wounds identified at baseline on the target limb had completely healed in 172/243 (70.8\%) of the RC5-6 subjects (RC5: 144/198 (72.7\%); RC6: 28/45 (62.2\%)). When assessing paired data, the percentage of subjects not seeing a wound care specialist improved significantly from $31.8 \%(\mathrm{~N}=69)$ at baseline to $66.4 \%(\mathrm{~N}=144)$ at 12 months; however, at 12 months $5.1 \%(\mathrm{~N}=11)$ began seeing a wound care specialist as compared to baseline. Of subjects seeing a wound care specialist at 12 months, $27.4 \%$ visited monthly, $20.5 \%$ once every 2 weeks, $39.7 \%$ weekly, and only $12.3 \%$ more than 2 times per week.

\section{Discussion}

CLI patients are under-represented in endovascular therapy clinical trials for multiple reasons: they are challenging to treat due to their comorbidities and long-term follow-up of this challenging population is near impossible because of their high mortality rate. In addition, treatment of CLI patients has not yet been standardized, and primary amputation was the first-line therapy for 22 to $67 \%$ of these patients until the mid-2010s, ${ }^{5,19}$ although less than $5 \%$ of the CLI patients should have primary amputation due to the severity of their disease. ${ }^{20}$

A recent meta-analysis of six trials that compared bypass surgery with angioplasty found no evidence to favor bypass surgery over angioplasty in terms of the effect on death, improvement of symptoms, amputation rate, need for further procedure, or long-term mortality. ${ }^{21}$ However, that study showed that angioplasty was associated with decreased procedural complications and shorter hospital stay compared with bypass surgery and concluded that endovascular treatment should be used in patients with CLI as they are high-risk surgical candidates. ${ }^{21}$ Mustapha et $\mathrm{al}^{22}$ found the same in their population-based cohort study using Medicare data of CLI patients treated with endovascular- or surgical revascularization or primary major amputation. Long-term survival and healthcare cost were comparable between the revascularization 

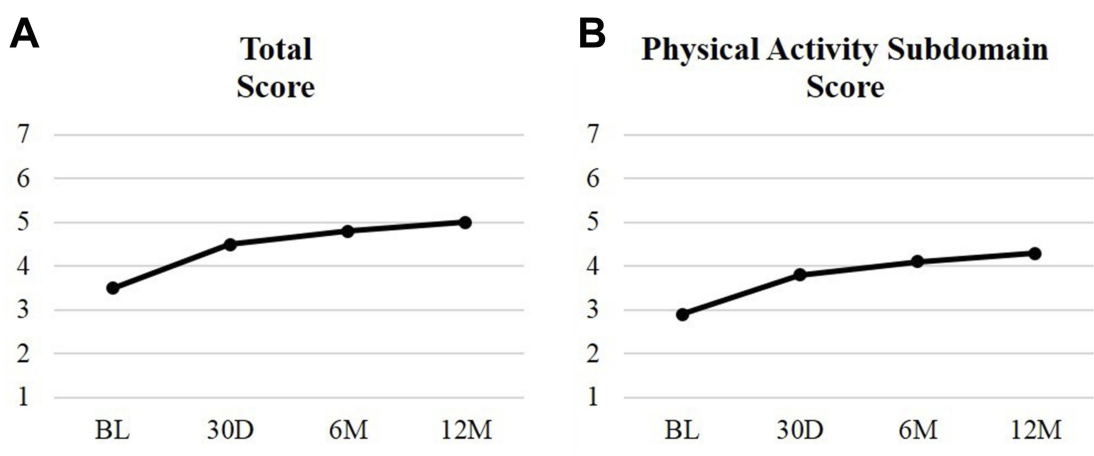

D

Pain

Subdomain Score

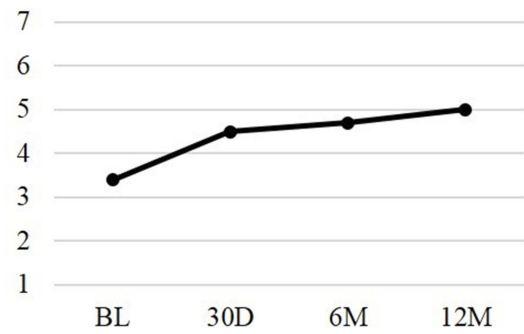

\section{E}

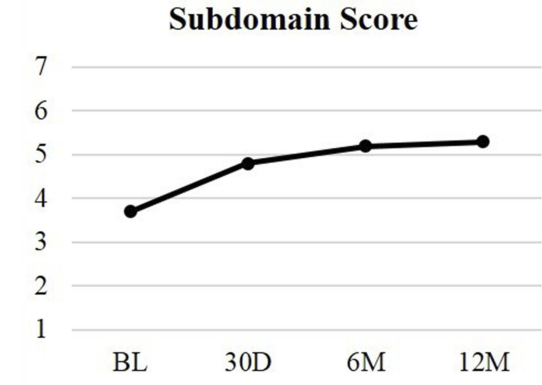

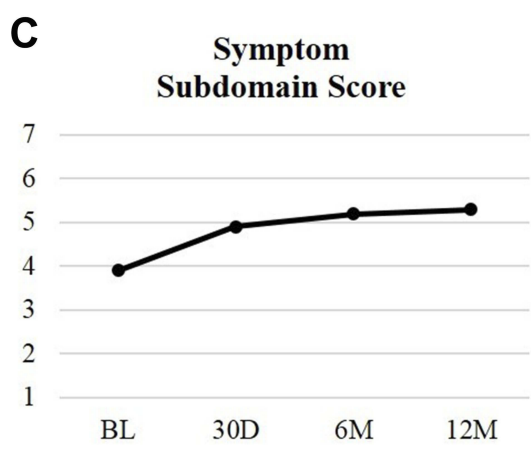

$\mathbf{F}$

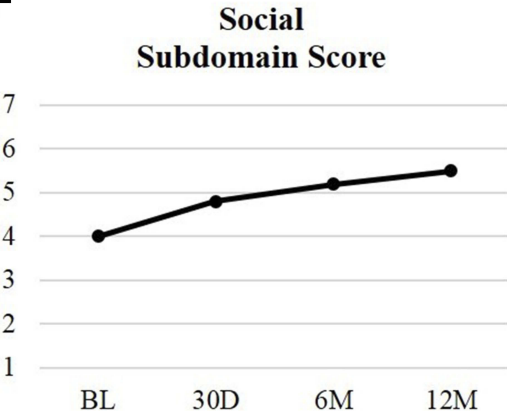

Figure 2 Changes in quality of life from baseline to 12 months (VascuQoL). Vascular Quality of Life Questionnaire: (A) Total score; (B) Physical activity subdomain score; (C) Symptom subdomain score; (D) Pain subdomain score; (E) Emotional subdomain score; and (F) Social subdomain score. Higher subdomain scores indicate better rating of health. Value presented as mean as recorded at each follow-up visit.

Abbreviations: BL, baseline; 30D, 30 days; 6M, 6 months; I2M, 12 months.
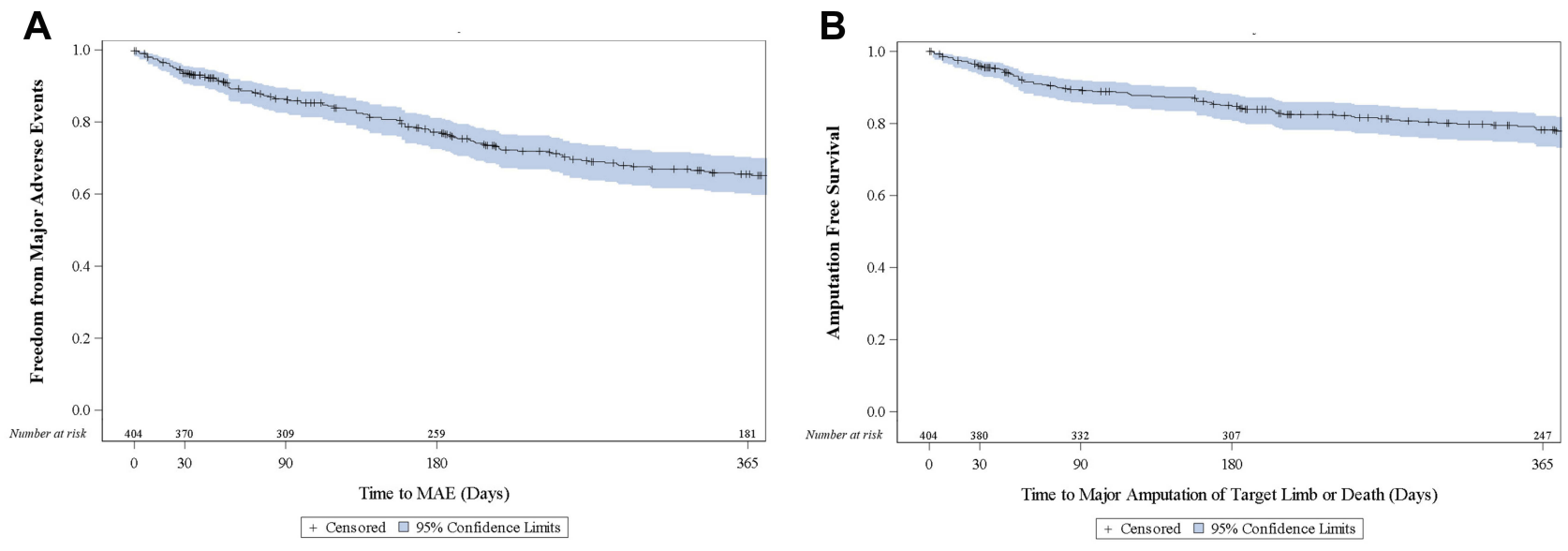

Figure 3 Kaplan-Meier curves for freedom from major adverse events (A) and amputation free survival (B) with number of subjects at risk. Abbreviation: MAE, major adverse events.

techniques but with lower major amputation rates following endovascular therapy. In addition, primary major amputation was associated with shorter survival time, higher risk of subsequent amputation, and higher costs compared with revascularization techniques.

Despite the evidence-based preventive effect of revascularization on limb amputation in CLI patients, recent studies reported that $13.5 \%{ }^{23}$ and $23 \%{ }^{15}$ of CLI patients were still managed with major amputation and minor amputation or conservative therapy, respectively, instead of endovascular revascularization.

Not all CLI patients are the same. CLI is a broad definition and includes patients with Rutherford classification 4 to 6 , where $\mathrm{RC} 4$ is characterized by ischemic rest pain, RC5 with minor tissue loss, and RC6 with major tissue loss - ulcer, gangrene. ${ }^{24}$ Previous studies found that 
Table 2 Freedom from Major Adverse Events and Amputation Free Survival at 30 Days, 6 Months, and I2 Months

\begin{tabular}{|l|l|l|}
\hline & 30 Days & $\mathbf{6}$ Months \\
\hline Freedom from MAE & $93.5(91.1,95.9)$ & $77.2(72.9,81.5)$ \\
Freedom from death* & $98.5(97.3,99.7)$ & $91.2(88.3,94.1)$ \\
Freedom from major amputation & $97.2(95.6,98.8)$ & $92.2(89.5,94.9)$ \\
Freedom from TVR & $97.0(95.3,98.7)$ & $82.8(78.8,86.7)$ \\
Amputation free survival & $96.0(94.1,97.9)$ & $84.7(81.1,88.4)$ \\
\hline
\end{tabular}

Notes: *Death includes all-death, including those beyond 30 days. Values presented as estimated survival rate (lower, upper bound of $95 \%$ confidence interval).

Abbreviations: MAE, major adverse events; TVR, target vessel revascularization.

Table 3 Target Limb Wound Healing

\begin{tabular}{|c|c|c|c|c|c|c|c|}
\hline & \multirow{2}{*}{$\begin{array}{l}\text { Baseline } \\
(\mathrm{N}=404)\end{array}$} & \multicolumn{2}{|l|}{30 Days } & \multicolumn{2}{|l|}{6 Months } & \multicolumn{2}{|l|}{12 Months } \\
\hline & & Value & $\begin{array}{l}\Delta \text { from } \\
\text { Baseline }\end{array}$ & Value & $\begin{array}{l}\Delta \text { from } \\
\text { Baseline }\end{array}$ & Value & $\begin{array}{l}\Delta \text { from } \\
\text { Baseline }\end{array}$ \\
\hline $\begin{array}{l}\text { Number of wounds on } \\
\text { target limb }\end{array}$ & $\begin{array}{l}1.5 \pm 0.9 \\
1.0[1.0,2.0] \\
(\mathrm{N}=404)\end{array}$ & $\begin{array}{l}1.2 \pm 1.0 \\
1.0[1.0,2.0] \\
(\mathrm{N}=324)\end{array}$ & $\begin{array}{l}-0.3 \pm 0.8 \\
0.0[-1.0 \\
0.0]^{*}\end{array}$ & $\begin{array}{l}0.7 \pm 0.8 \\
0.0[0.0,1.0] \\
(N=235)\end{array}$ & $\begin{array}{l}-0.9 \pm 1.1 \\
-1.0[-1.0 \\
0.0]^{*}\end{array}$ & $\begin{array}{l}0.4 \pm 0.7 \\
0.0[0.0,1.0] \\
(\mathrm{N}=207)\end{array}$ & $\begin{array}{l}-1.2 \pm 1.1 \\
-1.0[-2.0, \\
-1.0]^{*}\end{array}$ \\
\hline
\end{tabular}

Notes: *Change in mean number of wounds from baseline significant via paired $t$-test $(\mathrm{p}<0.00 \mathrm{I})$. Values presented as mean \pm standard deviation/median $[\mathrm{IQR}]$.

the comorbidities and lesion characteristics of patients with rest pain (RC4) differed significantly from those with tissue loss (RC5-6). ${ }^{25,26}$ RC4 patients were significantly less likely than RC5-6 to have diabetes, end-stage renal disease, or chronic heart failure. ${ }^{25-27}$ Also, RC5-6 patients had longer lesions, more TASC C and D lesions, and fewer patent below-the-ankle arteries compared to RC4 patients. $^{26}$ In addition, CLI patients without wounds had better prognosis after intervention than those with wounds. $^{25}$ RC4 patients are also treated differently compared to RC5-6, as they more often undergo revascularization and less often undergo primary amputation. Retrospectively reviewing diagnosis and procedural data from the largest public health insurance in Germany, the authors found that only $\sim 50 \%$ of RC5-6 patients had any revascularization compared to $71 \%$ of $\mathrm{RC} 4$ patients and $27.5 \%$ of them had in-hospital amputation compared to only $1.6 \%$ of $\mathrm{RC}^{2} .^{27}$ Reinecke and co-authors ${ }^{27}$ found a high mortality rate in RC5-6 patients which was only comparable with that of some aggressive types of cancer, as they noted it appropriately.

For the reasons mentioned above and also per the reporting standards of the Society of Vascular Surgery for endovascular treatment of $\mathrm{PAD},{ }^{28}$ as 'rest pain and tissue loss patients should not be grouped together in reporting outcomes', we present the outcomes for the LIBERTY RC5-6 patients only, and not for all CLI patients (RC4-6). This is the first study to show the endovascular treatment outcomes in RC5-6 patients in the US. Notably, in the LIBERTY 360 RC5-6 patients, $65.1 \%$ of lesions were below-the-knee only, $46.4 \%$ were longer than $10 \mathrm{~cm}$ and approximately $60 \%$ were calcified. The preferred devices were balloon and/or atherectomy and orbital atherectomy was the most frequently used atherectomy device. Procedural complications rarely $(1.7 \%)$ resulted in post-procedural hospitalization and $89.1 \%$ of RC5-6 patients were discharged to home. Agarwal et al, ${ }^{23}$ using State Inpatient Databases from three US states from 2009 to 2013, studied trends and factors affecting readmission in CLI patients, $16.6 \%$ of whom had endovascular revascularization alone, and found that only $33.6 \%$ of primary CLI admissions were discharged home from the hospital. On the other hand, in a retrospective study of 219 CLI patients treated with atherectomy and balloon angioplasty in an outpatient center, all patients were discharged home the same day, including 51.6\% RC5-6 patients. $^{29}$

Considering the advanced disease state in RC5-6 patients, there was a high rate of 12-month amputation free survival (AFS, 78.1\%). The 1-year AFS was $83.1 \%$ in the abovementioned outpatient study, ${ }^{29}$ while in another retrospective study of 809 RC5-6 patients with diabetes, the 1-year AFS was $75 \%$ for the endovascular group compared with $69 \%$ in the bypass group. ${ }^{30}$ Only $10.4 \%$ of the LIBERTY RC5-6 patients had a major amputation at 1 year - much lower than the $22 \%$ to $67 \%{ }^{5,31-34}$ primary major amputation rates seen 
in the literature for CLI patients that did not receive endovascular intervention (Figure 4). ${ }^{35}$

The mortality rate in LIBERTY RC5-6 patients was $13.3 \%$ at 1 year, very comparable to the outpatient study where the death rate was $11.4 \%$ for the entire cohort ${ }^{29}$ and much lower than the $30 \% 1$-year mortality rate in a retrospective US study $^{36}$ of patients who underwent lower extremity amputation. This rate is very similar though to the mortality rate in a large German retrospective study, ${ }^{27}$ where $34.2 \%$ of the RC6 patients died within the first 12 months after index hospitalization. Only $29.5 \%$ of these patients were treated with endovascular therapy and less than half of them had any revascularization procedure during index hospitalization.

It has been shown that endovascular revascularization improves wound healing in CLI patients ${ }^{37}$ and direct blood flow to the wounds is a positive predictor of wound healing. ${ }^{38}$ There was a significant improvement in the number of wounds on the target limb from baseline to 12 months in LIBERTY RC5-6 patients.

Quality of life (QoL), as measured by the total score and all subdomains of the VascuQoL, also improved significantly from baseline to 12 months. A recently published Japanese prospective study found the same; the health-related QoL was significantly improved compared to baseline in the CLI patients alive at 1 year after revascularization. ${ }^{39} \mathrm{~A}$ handful of observational studies that compared the effects of primary amputation and revascularization on QoL concluded that revascularization should be the preferred approach in patients with CLI. However, critics say that CLI patients have poor health prospects and life expectancy, irrespective of the treatment mode, ${ }^{40}$ and a focus on QoL research is needed to prescribe the ideal treatment for patients suffering from CLI. ${ }^{41}$ This study adds more evidence to the scarce literature and LIBERTY data supporting a revascularization approach for CLI will likely be corroborated by the BEST-CLI trial ${ }^{42}$ that compares surgical bypass and endovascular therapy in CLI patients and also provide data about the impact of these treatments on the QoL of the study population.

\section{Limitations}

This was a post hoc analysis of LIBERTY 360 - an observational, non-randomized study of endovascular therapies and was not powered to assess clinical outcomes in RC5-6 CLI patients. As this study was sponsored by a company whose principal endovascular strategy is atherectomy, bias may be attributed to physician selection of orbital atherectomy in a high number of cases. Additionally, wound data collection was limited in the LIBERTY 360 study; exact wound area, wound volume, and the date of wound healing were not collected. Possible over or underreporting of outcomes is possible due to subject withdrawal prior to 12 months.

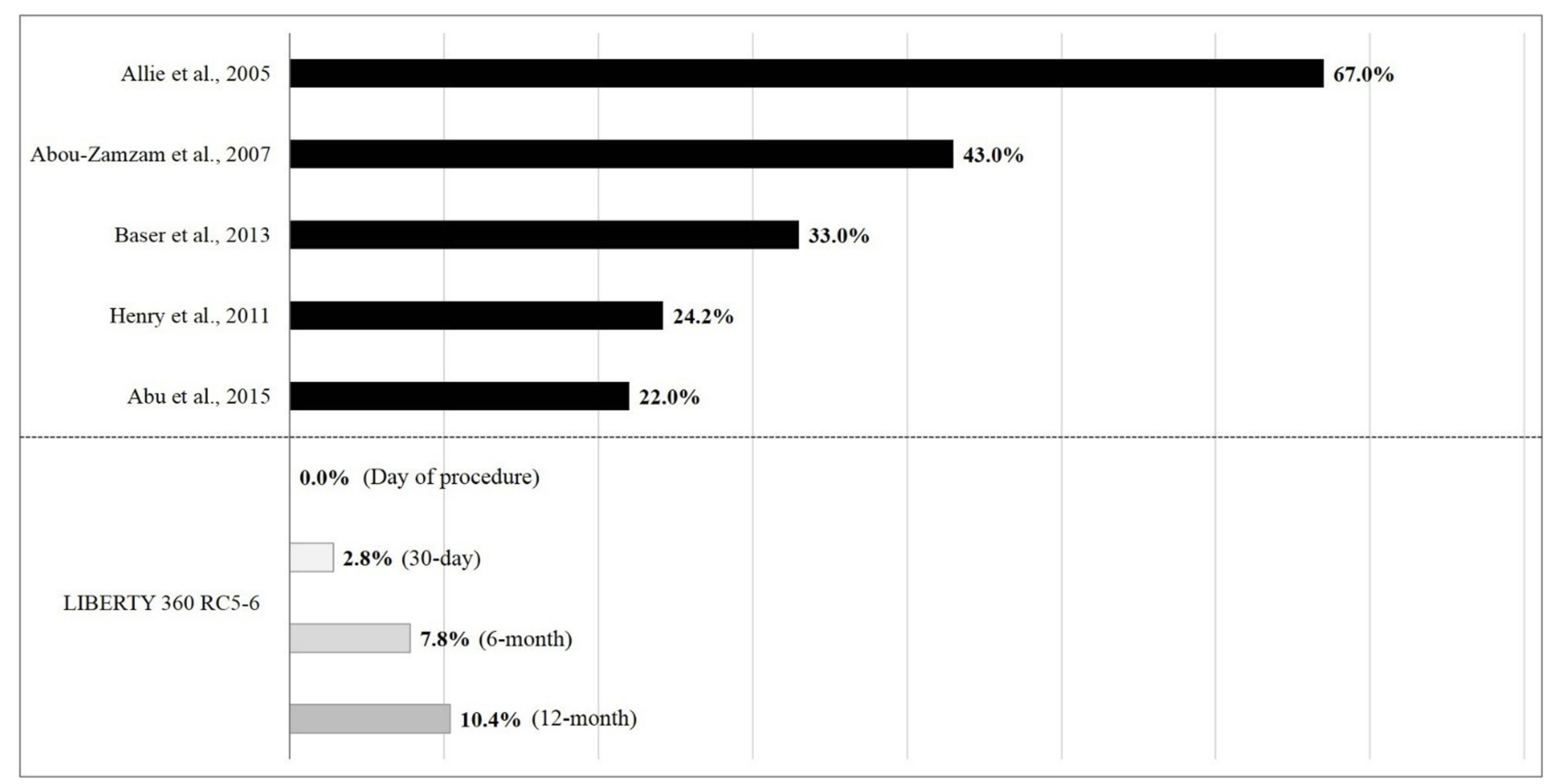

Figure 4 Critical limb ischemia (CLI) patients without revascularization (primary amputation treatment) vs LIBERTY 360 RC5-6 CLI patients (primary endovascular treatment). This summary graph shows the primary amputation rates presented in the literature and the major target limb amputation rates reported in LIBERTY, but it is not a head-to-head comparison since the analyses described vary in design. 


\section{Conclusions}

LIBERTY investigated real-world PAD patients with independent oversight of outcomes. The findings in this novel "all-comers" PAD study reveal hope for RC5-6 CLI patients and suggest that "primary amputation" in RC5-6 may not be necessary - peripheral endovascular device intervention can be successful in this patient population.

\section{Abbreviations}

AFS, amputation free survival; ATK, above-the-knee; BMS, bare-metal stent; BTK, below-the-knee; CLI, critical limb ischemia; DCB, drug-coated balloon; DES, drugeluting stent; MAE, major adverse events; OAS, orbital atherectomy system; PAD, peripheral artery disease; PARC, Peripheral Academic Research Consortium; PTA, percutaneous transluminal angioplasty; QoL, quality of life; RC, Rutherford Classification; TASC, Trans-Atlantic InterSociety Consensus; TVR, target vessel revascularization.

\section{Data Sharing Statement}

Individual-deidentified participant data and study-related documents will not be made available.

\section{Acknowledgements}

The authors would like to thank Ryan Bolduan, BA, for his critical review of this manuscript. This paper/the abstract of this paper was presented at the Society for Cardiovascular Angiography and Interventions' (SCAI) 41st Annual Scientific Sessions as a poster presentation with interim findings. The poster's abstract was published in "Poster Abstracts" in Catheterization and Cardiovascular Interventions: https:// doi.org/10.1002/ccd.27553.

\section{Author Contributions}

All authors contributed to data analysis, drafting and revising the article, gave final approval of the version to be published, and agree to be accountable for all aspects of the work. Each author participated sufficiently in the work to take public responsibility for appropriate portions of the content.

\section{Funding}

This research received no specific grant from any funding agency in the public, commercial, or not-for-profit sectors. Cardiovascular Systems, Inc. sponsored the LIBERTY 360 Study (ClinicalTrials.gov Identifier: NCT01855412).

\section{Disclosure}

JAM reports consulting agreements with Cardiovascular Systems, Inc., Medtronic, Bard Peripheral Vascular, Terumo, and Philips. Equity ownership CardioFlow. ZI is employed by and owns stock in CSI, during the conduct of the study. DO reports consulting agreement with CSI, a consulting agreement and grants from Boston Scientific, outside the submitted work. EJA reports consulting agreements with Cardiovascular Systems Inc., Abbott vascular, Boston scientific, Intact vascular, Gore, Medtronic, and Philips, outside the submitted work. FS reports speaker and consulting fees from CSI. ANB is employed by and owns stock in CSI. BJM is employed by and owns stock in CSI. GLA reports personal fees from Cardiovascular Systems, Philips, Abbott Vascular, Cook Medical and Gore, outside of the submitted work; and received consulting fees from Bard Peripheral Vascular, Terumo Interventional Systems, Medtronic, Boston Scientific, Spectranetics, and CSI. The authors report no other conflicts of interest in this work.

\section{References}

1. Yost M. Critical Limb Ischemia. Vol I United States Epidemiology Atlanta (GA). The Sage Group; 2010.

2. Schiavetta A, Maione C, Botti C, et al. A Phase II trial of autologous transplantation of bone marrow stem cells for critical limb ischemia: results of the Naples and Pietra ligure evaluation of stem cells study. Stem Cells Transl Med. 2012;1(7):572-578. doi:10.5966/sctm.2012-0021

3. Varu VN, Hogg ME, Kibbe MR. Critical limb ischemia. J Vasc Surg. 2010;51(1):230-241. doi:10.1016/j.jvs.2009.08.073

4. Eggers PW, Gohdes D, Pugh J. Nontraumatic lower extremity amputations in the Medicare end-stage renal disease population. Kidney Int. 1999;56(4):1524-1533. doi:10.1046/j.1523-1755.1999.00668.x

5. Abu Dabrh AM, Steffen MW, Undavalli C, et al. The natural history of untreated severe or critical limb ischemia. J Vasc Surg. 2015;62 (6):1642-1651.e3. doi:10.1016/j.jvs.2015.07.065

6. Jindeel A, Narahara KA. Nontraumatic amputation: incidence and cost analysis. Int J Low Extrem Wounds. 2012;11(3):177-179. doi:10.1177/1534734612457031

7. Dillingham TR, Pezzin LE, Shore AD. Reamputation, mortality, and health care costs among persons with dysvascular lower-limb amputations. Arch Phys Med Rehabil. 2005;86(3):480-486. doi:10.1016/j.apmr.2004.06.072

8. Pasquina PF, Miller M, Carvalho AJ, et al. Special considerations for multiple limb amputation. Curr Phys Med Rehabil Rep. 2014;2 (4):273-289. doi:10.1007/s40141-014-0067-9

9. Schofield CJ, Libby G, Brennan GM, et al. Mortality and hospitalization in patients after amputation: a comparison between patients with and without diabetes. Diabetes Care. 2006;29(10):2252-2256. doi: $10.2337 / \mathrm{dc} 06-0926$

10. Tentolouris N, Al-Sabbagh S, Walker MG, Boulton AJM, Jude EB. Mortality in diabetic and nondiabetic patients after amputations performed from 1990 to 1995: a 5-year follow-up study. Diabetes Care. 2004;27(7):1598-1604. doi:10.2337/diacare.27.7.1598

11. Faglia E, Clerici G, Clerissi J, et al. Early and five-year amputation and survival rate of diabetic patients with critical limb ischemia: data of a cohort study of 564 patients. Eur J Vasc Endovasc Surg. 2006;32 (5):484-490. doi:10.1016/j.ejvs.2006.03.006 
12. Gerhard-Herman MD, Gornik HL, Barrett C, et al. 2016 AHA/ACC guideline on the management of patients with lower extremity peripheral artery disease: executive summary: a report of the american college of cardiology/american heart association task force on clinical practice guidelines. J Am Coll Cardiol. 2017;69(11):1465-1508. doi:10.1016/j.jacc.2016.11.008

13. Goodney PP, Tarulli M, Faerber AE, Schanzer A, Zwolak RM. Fifteen-year trends in lower limb amputation, revascularization, and preventive measures among medicare patients. JAMA Surg. 2015;150 (1):84-86. doi:10.1001/jamasurg.2014.1007

14. Agarwal S, Sud K, Shishehbor MH. Nationwide trends of hospital admission and outcomes among critical limb ischemia patients: from 2003-2011. J Am Coll Cardiol. 2016;67(16):1901-1913. doi:10.1016/j. jacc.2016.02.040

15. Armstrong EJ, Ryan MP, Baker ER, Martinsen BJ, Kotlarz H, Gunnarsson C. Risk of major amputation or death among patients with critical limb ischemia initially treated with endovascular intervention, surgical bypass, minor amputation, or conservative management. J Med Econ. 2017;20(11):1148-1154. doi:10.1080/ 13696998.2017.1361961

16. Adams GL, Mustapha J, Gray W, et al. The LIBERTY study: design of a prospective, observational, multicenter trial to evaluate the acute and long-term clinical and economic outcomes of real-world endovascular device interventions in treating peripheral artery disease. $\mathrm{Am}$ Heart J. 2016;174:14-21. doi:10.1016/j.ahj.2015.12.013

17. Mustapha J, Gray W, Martinsen BJ, et al. One-year results of the LIBERTY 360 study: evaluation of acute and midterm clinical outcomes of peripheral endovascular device interventions. $J$ Endovasc Ther. 2019;26(2):143-154. doi:10.1177/1526602819827295

18. Patel MR, Conte MS, Cutlip DE, et al. Evaluation and treatment of patients with lower extremity peripheral artery disease: consensus definitions from Peripheral Academic Research Consortium (PARC). $\mathrm{J} \mathrm{Am}$ Coll Cardiol. 2015;65(9):931-941. doi:10.1016/j.jacc.2014.12.036

19. Allie DE, Hebert CJ, Lirtzman MD, et al. Critical limb ischemia: a global epidemic.A critical analysis of current treatment unmasks the clinical and economic costs of CLI. EuroIntervention. 2005;1 (1):75-84.

20. Rudofker EW, Hogan SE, Armstrong EJ. Preventing major amputations in patients with critical limb ischemia. Curr Cardiol Rep. 2018;20(9):74. doi:10.1007/s11886-018-1019-2

21. Antoniou GA, Georgiadis GS, Antoniou SA, Makar RR, Smout JD, Torella F. Bypass surgery for chronic lower limb ischaemia. Cochrane Database Syst Rev. 2017;4:CD002000. doi:10.1002/ 14651858.CD002000.pub3

22. Mustapha JA, Katzen BT, Neville RF, et al. Determinants of long-term outcomes and costs in the management of critical limb ischemia: a population-based cohort study. J Am Heart Assoc. 2018;7 (16):e009724. doi:10.1161/JAHA.118.009724

23. Agarwal S, Pitcavage JM, Sud K, Thakkar B. Burden of readmissions among patients with critical limb ischemia. $\mathrm{J} \mathrm{Am}$ Coll Cardiol. 2017;69(15):1897-1908. doi:10.1016/j.jacc.2017.02.040

24. Hardman RL, Jazaeri O, Yi J, Smith M, Gupta R. Overview of classification systems in peripheral artery disease. Semin Interv Radiol. 2014;31(4):378-388. doi:10.1055/s-0034-1393976

25. O’Brien-Irr MS, Dosluoglu HH, Harris LM, Dryjski ML. Outcomes after endovascular intervention for chronic critical limb ischemia J Vasc Surg. 2011;53(6):1575-1581. doi:10.1016/j.jvs.2011.01.068

26. Tsuchiya T, Iida O, Shiraki T, et al. Clinical characteristics of patients with Rutherford category IV, compared with V and VI. SAGE Open Med. 2015;3:2050312115597087. doi:10.1177/2050312115597087
27. Reinecke H, Unrath M, Freisinger E, et al. Peripheral arterial disease and critical limb ischaemia: still poor outcomes and lack of guideline adherence. Eur Heart J. 2015;36(15):932-938. doi:10.1093/eurheartj/ ehv006

28. Stoner MC, Calligaro KD, Chaer RA, et al. Reporting standards of the society for vascular surgery for endovascular treatment of chronic lower extremity peripheral artery disease: executive summary. $J$ Vasc Surg. 2016;64(1):227-228. doi:10.1016/j.jvs.2016.03.432

29. Dattilo R, Dattilo A, Colby S. Outcomes of patients treated for critical limb ischemia in an outpatient endovascular center. Vasc Manag. 2018;15(6):E49-E52.

30. Lo ZJ, Lin Z, Pua U, et al. Diabetic foot limb salvage-a series of 809 attempts and predictors for endovascular limb salvage failure. Ann Vasc Surg. 2018;49:9-16. doi:10.1016/j.avsg.2018.01.061

31. Allie DE, Hebert CJ, Ingraldi A, Patlola RR, Walker CM. 24-carat gold, 14-carat gold, or platinum standards in the treatment of critical limb ischemia: bypass surgery or endovascular intervention? $J$ Endovasc Ther. 2009;16(Suppl 1):I134-I146. doi:10.1583/082599.1

32. Henry AJ, Hevelone ND, Belkin M, Nguyen LL. Socioeconomic and hospital-related predictors of amputation for critical limb ischemia. J Vasc Surg. 2011;53(2):330-339.e1. doi:10.1016/j.jvs.2010.08.077

33. Abou-Zamzam AM, Gomez NR, Molkara A, et al. A prospective analysis of critical limb ischemia: factors leading to major primary amputation versus revascularization. Ann Vasc Surg. 2007;21 (4):458-463. doi:10.1016/j.avsg.2006.12.006

34. Baser O, Verpillat P, Gabriel S, Li W. Prevalence, incidence, and outcomes of critical limb ischemia in the US medicare population | vascular disease management. Vasc Dis Manag. 2013;10(2):E26-E36.

35. Mustapha J, Martinsen BJ, Igyarto Z. LIBERTY $360^{\circ}$ study presentation at amp 2016 reveals hope for Rutherford-6 CLI patients. Cath Lab Dig. 2016;24(10).

36. Shah SK, Bena JF, Allemang MT, et al. Lower extremity amputations: factors associated with mortality or contralateral amputation. Vasc Endovascular Surg. 2013;47(8):608-613. doi:10.1177/ 1538574413503715

37. Bae J-I, Won JH, Han SH, et al. Endovascular revascularization for patients with critical limb ischemia: impact on wound healing and long term clinical results in 189 limbs. Korean J Radiol. 2013;14 (3):430-438. doi:10.3348/kjr.2013.14.3.430

38. Kobayashi N, Hirano K, Nakano M, et al. Wound healing and wound location in critical limb ischemia following endovascular treatment. Circ J. 2014;78(7):1746-1753. doi:10.1253/circj.CJ-14-0171

39. Iida O, Takahara M, Soga Y, et al. Prognostic impact of revascularization in poor-risk patients with critical limb ischemia: the priority registry (Poor-risk patients with and without revascularization therapy for critical limb ischemia). JACC Cardiovasc Interv. 2017;10 (11):1147-1157. doi:10.1016/j.jcin.2017.03.012

40. Bosma J, Vahl A, Wisselink W. Systematic review on health-related quality of life after revascularization and primary amputation in patients with critical limb ischemia. Ann Vasc Surg. 2013;27 (8):1105-1114. doi:10.1016/j.avsg.2013.01.010

41. Steunenberg SL, Raats JW, Te Slaa A, de Vries J, van der Laan L. Quality of life in patients suffering from critical limb ischemia. Ann Vasc Surg. 2016;36:310-319. doi:10.1016/j.avsg.2016.05.087

42. Menard MT, Farber A, Assmann SF, et al. Design and rationale of the best endovascular versus best surgical therapy for patients with critical limb ischemia (BEST-CLI) trial. J Am Heart Assoc. 2016;5:7. doi:10.1161/JAHA.116.003219 


\section{Publish your work in this journal}

Vascular Health and Risk Management is an international, peerreviewed journal of therapeutics and risk management, focusing on concise rapid reporting of clinical studies on the processes involved in the maintenance of vascular health; the monitoring, prevention and treatment of vascular disease and its sequelae; and the involvement of metabolic disorders, particularly diabetes. This journal is indexed on PubMed Central and MedLine. The manuscript management system is completely online and includes a very quick and fair peerreview system, which is all easy to use. Visit http://www.dovepress. com/testimonials.php to read real quotes from published authors.

Submit your manuscript here: https://www.dovepress.com/vascular-health-and-risk-management-journal 